\title{
Metallic solutions and calorimetry
}

\author{
Jean Pierre Bros
}

Université de Provence, SETT-UA 1168, Av. Escadrille Normandie-Niemen, 13397 Marseille cedex 13, France.

\begin{abstract}
In materials science, accurate high temperature thermodynamic measurements are needed to predict and to understand the properties of n-components systems. Two examples have been chosen to highlight this problem : i) from molar heat capacity determinations, the miscibility gap of the solid HgTe-CdTe system has been found ; ii) in spite of several empirical and theoretical models, measurements of the enthalpy of formation of Cd-Ga-In$\mathrm{Sn}-\mathrm{Zn}$ liquid alloys are unavoidable. These examples show the necessity to develop very precise calorimetric methods in the high temperature range.
\end{abstract}

\section{INTRODUCTION}

For high temperature science, thermodynamics is a powerful tool which allows to understand the properties of materials ( alloys, ceramics,...). From results obtained at low temperature we can predict what it will happen at high temperature : that is the main interest of this science. Moreover taking into account the difficulties encountered to perform high temperature measurements, data predicted by using the well known thermodynamic relations seem more reliable and more accurate than those we could hope to determine.

But fairly often, in materials science, high temperature determinations are unavoidable. Usually it is uneasy and often very expensive to work in such conditions. Thus the choice of the experimental technique and of the decisive measurement is the essential point.

In high temperature range, all techniques based on the study of thermal effects developed during experiments ( calorimetry, thermal analysis) are efficient. So, from some examples, the main purpose of this lecture is to highlight the interest of accurate thermal measurements at high temperature in materials science.

\section{METHODS}

In the field of high temperature thermochemistry, for systems containing metals, oxides or salts, Gibbs free energy measurements are very scarce. Generally the most often measured functions are enthalpies of formation, enthalpies of transition, equilibrium temperatures, heat capacities,...So, the main techniques used are thermal analysis and calorimetry. The number of apparatus (calorimeters and thermal analysers) which have been designed to meet requirements for the best solution of an actual problem is considerable. But these two techniques and apparatus have been described in several text-books and reviews. The choice of an apparatus depends on a large number of factors : the experimental temperature range, the optimal accuracy, the size of the thermal effect, the reactivity of samples,...The difficulties increase considerably with temperature ; for these two techniques, the common difficulties arise from the choice of containers ( to avoid contamination), the vaporization of materials, the calibration procedures, the heat leaks by conduction, radiation,...

The specific difficulties encountered up to $1000 \mathrm{~K}$ in differential thermal analysis and the solutions adopted have been recently described by J.L. Jorda in : "Analyses thermiques à haute température : mode ou nécessité "( ref.1).

Several descriptions of calorimeters used in metallurgy have been published ( ref. 2 and 3 ). It seems that the majority of the high temperature apparatus belongs to the classes of isoperibol high temperature calorimeters and of conduction high temperature calorimeters. Unfortunately, we have to regret a decline in adiabatic high temperature calorimetry which has been a considerable source of data in metallurgy. With isoperibol high temperature calorimeters, Ferro and coworkers ( ref. 4 ), Predel and coworkers ( ref. 3 ) carried out a large number of enthalpies of formation of solid and liquid alloys. The Calvet high temperature, operable on the temperature range $500-1300 \mathrm{~K}$ is used by several groups or scientists ( R. Castanet, C. Colinet, M. Gambino, E. Hayer, O.J. Kleppa, Z. Moser,... publications of whom are well-known ). Up to $1300 \mathrm{~K}$, calorimeters available to determine enthalpies of formation of alloys are not numerous. A very-high temperature operable until $1800 \mathrm{~K}$ is used by M. Gaune-Escard, J. Hertz, J.L. Jorda, A. Navrotsky,...).

Nowaday, a new class of calorimeter, the differential scanning calorimeters (D.S.C.) allows to obtain quickly the molar heat capacities and the enthalpies of transition. Unfortunately, the upper temperature of these apparutus is about $1000 \mathrm{~K}$. 


\section{APPLICATIONS}

To highlight the advantage of precise high temperature calorimetric measurements, two examples have been chosen ; they concern the determination of : i) the miscibility gap of CdTe-HgTe solid alloy, ii) the heat of formation of the Cd-Ga-In-Sn-Zn liquid alloy.

\section{CdTe-HgTe system}

Two experimental ways ( calorimetric and potentiometric) were followed to investigate the CdTe-HgTe solid phase region.

Much has been published about CdTe-HgTe system ; we will not report here, in details, the thermodynamic data but we would recall that the equilibrium phase diagram is of the simplest type : HgTe and CdTe form a complete series of solid solutions which have the $\mathrm{ZnS}$ structure. The $\mathrm{Hg}$ and $\mathrm{Cd}$ atoms are randomly distributed over the sites of one sublattice. Among the many thermodynamic data published, the heat capacities of CdTe-HgTe alloys are missing. Unfortunately, for a better phase diagram assessment, the values of molar heat capacity of components and alloys versus temperature are required. Moreover data concerning the solid phase are very scarce.

Preparation and analysis of alloys. Well known mass of tellurium, cadmium (in powder) and mercury of high purity ( 99.999 at. \%) were placed in quartz crucibles ( $10 \mathrm{~mm}$ in diameter) sealed under vacuum $\left(10^{-3} \mathrm{~Pa}\right)$ and heated at $673 \mathrm{~K}$. Every three hours, the temperature of the furnace was increased of $50 \mathrm{~K}$. At $723 \mathrm{~K}$, the temperature was stabilized during one week then slowly decreased in one day. Ingots so obtained were ground. Using a special mould, pellets were prepared (14 $\mathrm{mm}$ in diameter, $10 \mathrm{~mm}$ high). These pellets were maintained under vacuum, in sealed ampoule, at $723 \mathrm{~K}$, during one week then slowly cooled until $523 \mathrm{~K}$. All these alloys were analysed by $\mathrm{X}$-ray diffraction using the $\mathrm{CuK}_{\alpha}$ radiation with a DRON apparatus. The variation of the lattice parameter ( $\mathrm{a} / \AA$ ) of the CdTe-HgTe solid solutions follows the Vegard's law and is given by :

$$
a / \AA=6,4637+2,02 \cdot 10^{-2} \times \mathrm{CdTe} \text { with a standard deviation } 2 S_{o}= \pm 0,002 \AA .
$$

\section{Cp measurements}

Ideally, determination of molar heat capacities should be made with an adiabatic calorimeter. But, along with the recent progress achieved in differential scanning calorimetry, it seems quite natural to employ this technique to carry out $\mathrm{C}_{\mathrm{p}}$ values of multicomponent systems on large temperature ranges and at several compositions in order to detect the critical lines. So, using a differential scanning calorimeter, $\mathrm{C}_{\mathrm{p}}$ values versus temperature of CdTe-HgTe solid alloys have been carried out.

The specific heat of a sample is calculated from the relationship :

and if $T=f(t)$

$$
\mathrm{C}_{\mathrm{p}}=(\mathrm{dH} / \mathrm{dT})_{\mathrm{p}}
$$

$$
((d H / d t) /(d T / d t))_{p} \text { then }(d H / d t)_{p}=C_{p}(d T / d t)
$$

where $\mathrm{H}, \mathrm{T}$ and $\mathrm{t}$ are respectively enthalpy, temperature and time.

If the temperature increases from $T_{1}$ to $T_{2}$ during the period $t_{2}-t_{1}$, the equation may be written :

$$
\int(\mathrm{dH} / \mathrm{dt})_{\mathrm{p}}=\int \mathrm{C}_{\mathrm{p}}(\mathrm{dT} / \mathrm{dt})
$$

with the assumption that the heat capacity is constant on a narrow temperature range, then

$$
\mathrm{C}_{\mathrm{p}}=[\mathrm{H}]_{\mathrm{t} 1} \mathrm{t}^{2} /[\mathrm{T}]_{\mathrm{t}} \mathrm{t}^{\mathrm{2}}
$$

Consequently, the pratical determination of $C_{p}=f(T)$ with a differential scanning calorimeter demands the knowledge of the temperature increase of the calorimeter containing the experimental and the reference cells and the variation of the enthalpy during the same period.

The apparatus (DSC 111-Setaram company) is designed as a Calvet calorimeter with two cylindrical cells ( reference and laboratory cells). It should be emphasized that two calibration methods have been employed : in one method, a standard NIST alumina crystal ( ref. 5) is used for comparison and, in the other, direct Jouleheating of an electrical resistance located in the cell is used. Such an apparatus can be operated between $173 \mathrm{~K}$ and $1023 \mathrm{~K}$.

Consequently, in measuring heat capacities, the following procedure was adopted ; with the same experimental conditions ( constant heat rate, identical scanned temperature range, identical argon flow,...) :

i) the "zero test", with two identical empty containers, allows to determine the thermal disequilibrium between the reference and laboratory cells,

ii) the "experimental test" performs with the sample in the experimental cell,

iii) the " calibration test" obtained by using either the Joule effect or a well known mass of standard NIST alumina crystal. The discrepancy between our experimental results and the reference data (NIST) was always less than $0.5 \%$. 
Great care has to be taken in protecting samples in the cell : alloys (about $200 \mathrm{mg}$ ) were placed in gastight stainless crucibles $(6 \mathrm{~mm}$ diameter , $20 \mathrm{~mm}$ lengh) and all experiments were performed under purified argon flow. On the temperature range $300-523 \mathrm{~K}$, every five Kelvins, the heat capacity of the sample have been determined. The heating rate is $1.5 \mathrm{~K} . \mathrm{mn}^{-1}$ during 200 seconds and the temperature is maintained constant during 400 seconds. Temperatures were determined at $\pm 0.5^{\circ} \mathrm{C}$ and molar heat capacities were measured with an accuracy of about $2 \%$.

Over the temperature range $300 \mathrm{~K}-523 \mathrm{~K}$, the molar heat capacity of CdTe, $\mathrm{HgTe}$ and of ten $\mathrm{HgTe}-\mathrm{CdTe}$ alloys $($ with $\mathrm{XCdTe}=0.0996,0.118,0.253,0.350,0.400,0.500,0.544,0.600,0.700$ and 0.800 ) has been determined.

Molar heat capacity of CdTe and HgTe. The molar heat capacity of these two compounds (CdTe and $\mathrm{HgTe}$ ) may be expressed as

$$
\begin{array}{ll}
\mathrm{C}_{\mathrm{p}}, \mathrm{CdTe}=23.902+0.00576 \mathrm{~T} & \text { in J.K-1. } \mathrm{mol}^{-1} \\
\mathrm{C}_{\mathrm{p}, \mathrm{HgTe}}=25.445+0.004068 \mathrm{~T} & \text { in J.K-1. } \mathrm{mol}^{-1}
\end{array}
$$

A good agreement is remarked with values obtained by using Kopp-Neuman rule; the heat capacities of elements (Te, $\mathrm{Cd}$ ) are from Hultgren et al. compilation ( ref. 6 ). These results have been compared to those carried out by Malkova ( ref. 7 ) and Kelemen ( ref. 8 ) for CdTe and HgTe respectively.

Molar heat capacity of CdTe-HgTe allovs. The experimental values of Cp of the CdTe-HgTe system have been integrally published ( ref. 9 ). Using the equations $\{1\}$ and $\{2\}$ and Neumann-Kopp rule, the molar heat capacities have been also calculated.

From these results it may be noticed that :

i) if $\mathrm{xCdTe}<0.253$, the $C_{p}=f(T)$ law is quasi-linear and reasonably reliable estimates are obtained with Neumann and Kopp rule (Fig. 1)

ii) if $x \mathrm{xdTe}>0.253, \mathrm{C}_{\mathrm{p}}=\mathrm{f}(\mathrm{T})$ plots ( Fig. 2) exibit a step at the temperature $\mathrm{T}_{\mathrm{s}}$ with a linear variation of $\mathrm{C}_{\mathrm{p}}$ if $T>T_{s}$. Below the temperature of the step, the variation of $C_{p}$ is irregular and $\Delta C_{p}=\left(C_{p}\right.$,exp.- $C_{p}$, calc. $)$ are large and positive. Up $\mathrm{T}_{\mathrm{S}}$, calculated (with $\mathrm{K}-\mathrm{N}$ rule) and experimental values are in rather good agreement.

Comparing the $C_{p}=f(T)$ curves obtained for all these alloys it can be concluded that $T_{s}$ corresponds to the appearance of an equilibrium in the solid state.

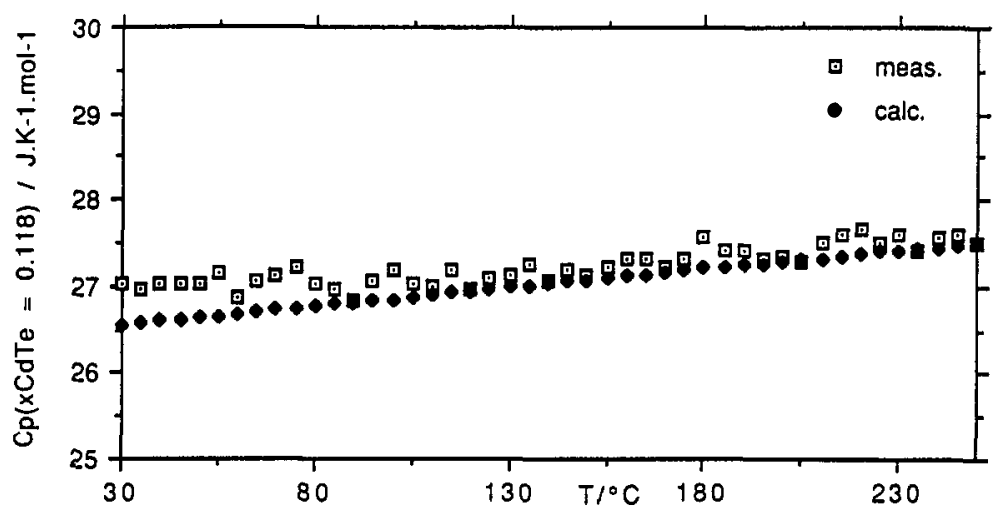

Fig. 1: Molar heat capacity of $\mathrm{CdTe}(0.118) \mathrm{HgTe}(0.882)$ solid alloy on the temperature range $30^{\circ} \mathrm{C}-250^{\circ} \mathrm{C}$.

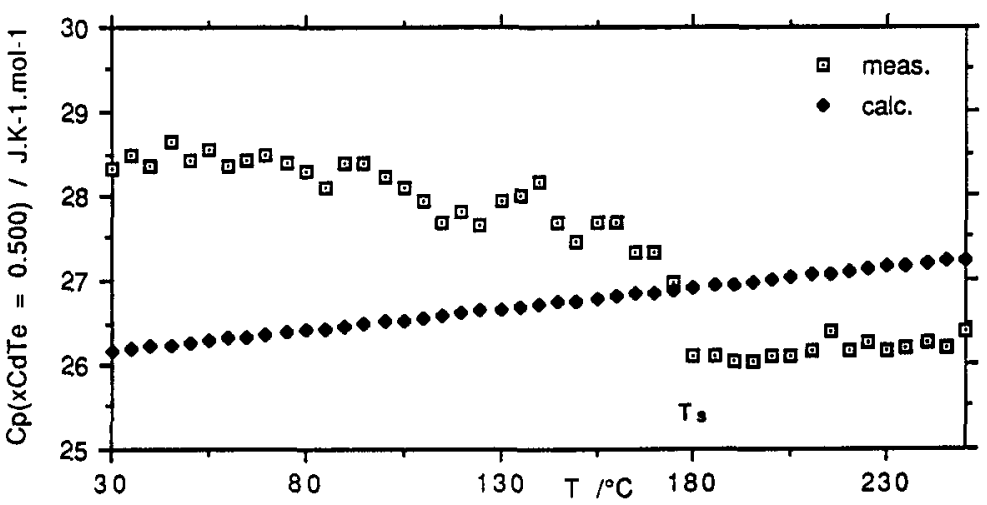

Fig. 2 : Molar heat capacity of $\mathrm{CdTe}(0.500) \mathrm{HgTe}(0.500)$ solid alloy on the temperature range $30^{\circ} \mathrm{C}-250^{\circ} \mathrm{C}$. 
The large value of $\Delta C_{p}$ may be due to the presence of two phases and to the thermal effect associated to the change of the equilibrium (solid $<-->$ solid (1) + solid (2) ) during the heating ( from $T_{1}$ to $T_{2}$ ) of the $C_{p}$ measurement. In the one-phase region $(\mathrm{T}=500 \mathrm{~K})$ between the solidus line and the miscibility gap, $\Delta \mathrm{Cp}$ is negative corresponding probably to an ordering process on the lattice.

\section{Emf measurements}

On the whole composition range of the solid $(\mathrm{CdTe})_{\mathbf{x}}(\mathrm{HgTe})_{1-x}$ system, variations of the partial free energy of cadmium telluride were determined by using the potentiometric technique. These measurements were carried out with solid alloys containing an excess of tellurium, by using the electrolytic cells represented diagrammatically thus :
Cell $n^{\circ} 1$
(-) $\mathrm{Cd}$ (sol.)/ $\mathrm{CaCl}_{2}+\mathrm{CdCl}_{2}$ in glycerol / ((CdTe) $\left.)_{\mathbf{x}}(\mathrm{HgTe}) 1-\mathrm{x}+\mathrm{Te}\right)$ (sol.)
Cell $n^{\circ} 2$
(-) $\mathrm{Cd}$ (liq.)/ $\mathrm{RbCl}+\mathrm{LiCl}+\mathrm{CdCl} 2$ melt $/\left((\mathrm{CdTe})_{x}(\mathrm{HgTe}) 1-\mathrm{x}+\mathrm{Te}\right)$ (sol.)

- The cell $\mathrm{n}^{\circ} 1$ is operable between $307 \mathrm{~K}$ and $416 \mathrm{~K}$ and the liquid electrolyte is made of pure glycerol saturated in $\mathrm{CaCl}_{2}$ and containing 0.05 weight per cent of $\mathrm{CdCl}_{2}$.

- The cell $\mathrm{n} 2$ is operable between $580 \mathrm{~K}$ and $700 \mathrm{~K}$. $\mathrm{RbCl}+\mathrm{LiCl}$ eutectic mixture with $0.05 \mathrm{wt}$ \% of cadmium chloride constitutes the electrolyte.

Reference and working electrodes are made of a tungsten wire attached to a pelletised mixture of metal or alloys in powder form. A special mould allows to press isostatically the powdered compounds intimately mixed around the W wire. This technique insures a good electric contact between electrodes ( pellets) and electric leads (W).

All requirements of a potentiometric study concerning the reversibility of the cell and the measurements of emf and temperatures were carefully observed : emf values were carried out at constant temperature with an digital voltmeter with a large input impedance : an emf value was accepted when the difference between two or three measurements was less than $\pm 0.3 \mathrm{mV}$. The experimental temperature was obtained at $\pm 1 \mathrm{~K}$.

Ten alloys $(\mathrm{xCdTe}=0.06,0.10,0.22,0.30,0.40,0.50,0.60,0.70,0.80,1.0$ with an excess of about 10 at.\% $\mathrm{Te}$ ) were studied by potentiometry.

All the emf experimental values have been reported in Fig. 3 ; solid and dashed lines correspond respectively of measured and interpolated (and extrapolated) values. On the basis of the compiled data (ref.10), the $E=f(T)$ values obtained with the cell $n^{\circ} 1$ in which liquid cadmium is the reference electrode were recalculated to be referred to the superheated solid cadmium. Emf ( experimental and bibliographic ( ref. 10)) values of Cd-Te cells are indicated in the upper part of Fig. 3.

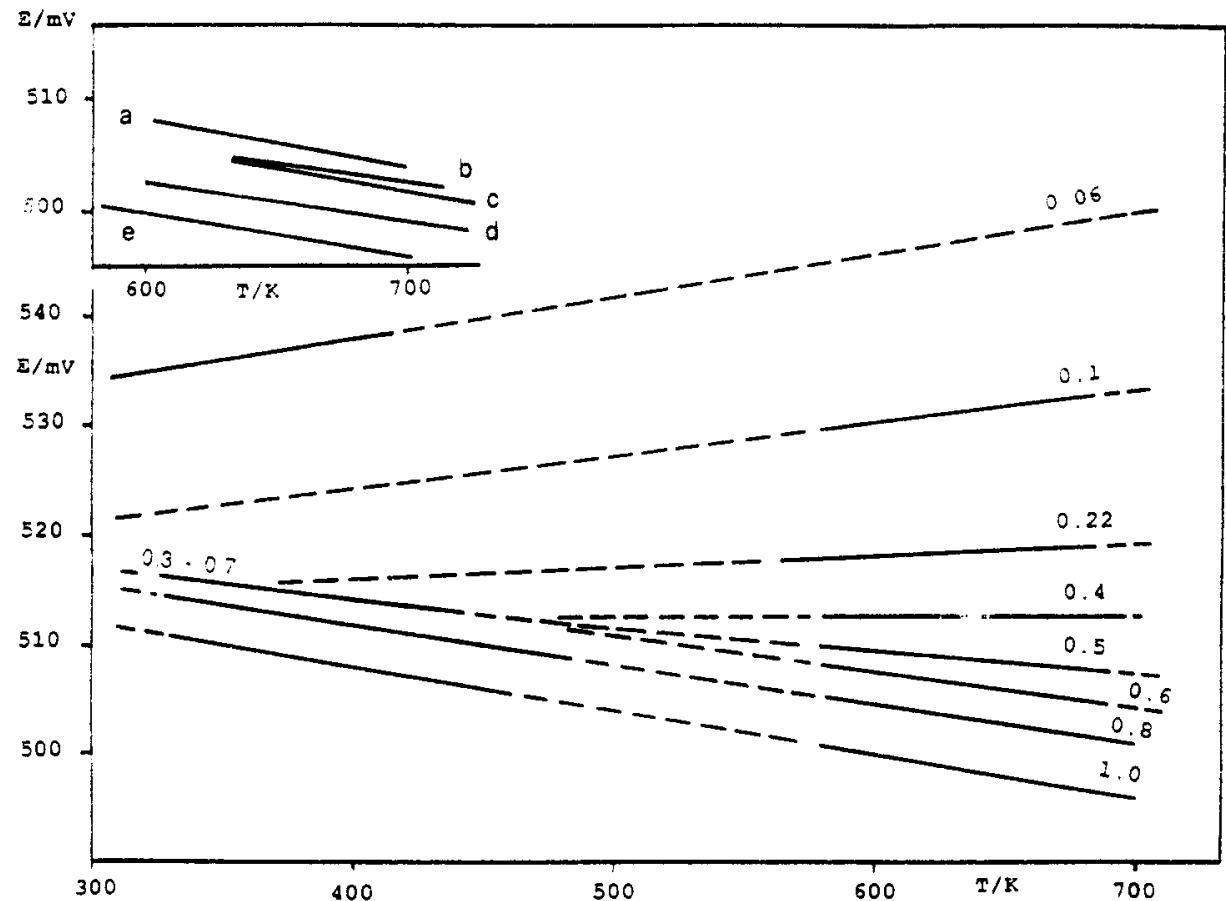

Fig. $3: \mathrm{E} / \mathrm{mV}=\mathrm{f}(\mathrm{T} / \mathrm{K})$ for the following molar fractions $0.1,0.8,0.6,0.5,0.4,0.22$, $0.1,0.06$. Full and dashed lines correspond to measured and interpolated (or extrapolated) values. In the upper part of the graph, bibliographic (a, b, c, d ( ref. 10) ) and experimental (e) results are reported. 


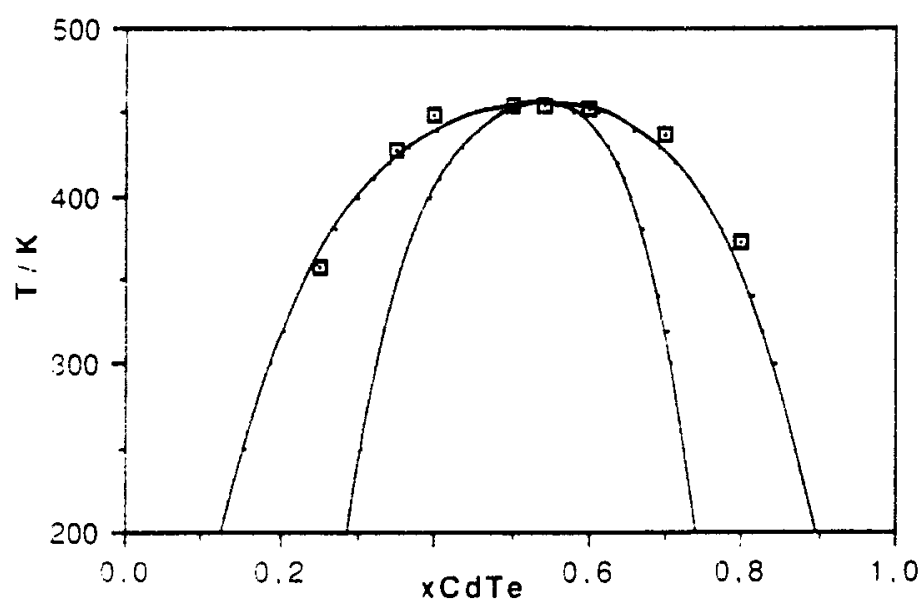

Fig. 4 : Micibility gap in the solid phase region of the CdTe-HgTe system.

Binodal and spinodal curves have been calculated from thermodynamic data (full lines).Experimental points ( $\square$ ) from calorimetric measurements.

The analysis of the plots $E=f(T)$ leads us to the following remarks :

-over the experimental temperature range, the regular variation of $\mathrm{E}$ with the molar fraction $\mathrm{XCdTe}$ ascertains the existence of a complete solid solubility at high temperature ;

- the "fan-wise arrangement" of the lines $E=f(T)$ - with a tendancy to the union at $T<500 \mathrm{~K}$ shows :

i) the increase of the stability of solid solutions with the temperature,

ii) the existence of a heterogeneous region at low temperature ( $326 \mathrm{~K}-423 \mathrm{~K}$ ).

This last remark evidences the independance of emf values with the molar fraction (xCdTe) when $0.3<\mathrm{xCdTe}<$ 0.7. In the heterogeneous region of the phase diagram, a least squares fit to the data conformed to a straight line in the temperature range of measurements. These results may be ascribed to the appearance of a miscibility gap $\left(S_{1}+S_{2}\right)$ at low temperature. Moreover the enthalpies of formation of solid solutions $\mathrm{Cd}_{\mathrm{x}} \mathrm{Hg}_{1-\mathrm{x}} \mathrm{Te}$ are positive on the molar fraction range $0.1<\mathrm{xCdTe}<0,9$ ( therefore in agreement with the existence of a miscibility gap) and practically egal to zero between $0-0.1$ and $0.9-1$.

The positive variation of the free energy of formation with $T$ indicates the decrease of the thermodynamic stability of the solid phase. With all these facts, a solid miscibility gap may be expected in this region under a critical temperature. The limit of this miscibility gap was calculated using the condition that the chemical potentials of components in a two phase region are equal i.e.

$$
(\mu \mathrm{CdTe})(\text { solid } 1)=(\mu \mathrm{CdTe})(\text { solid } 2) \quad \text { and }(\mu \mathrm{HgTe})(\text { solid } 1)=(\mu \mathrm{HgTe})(\text { solid } 2)
$$

The calculated coordinates of the critical point are: $\mathrm{xCdTe}=0,535$ et $\mathrm{T}=456,5 \mathrm{~K}$.

Fig.4 illustrates the good agreement between the limit of miscibility gap obtained by potentiometric and calorimetric experiments. The equation of the miscibility gap has been deduced ( with $\mathrm{x}=\mathrm{xCdTe}$ ) :

$$
\mathrm{T} / \mathrm{K}=-557.11+7216.9 \mathrm{x}-1.960310^{4} \mathrm{x}^{2}+2.409010^{4} \mathrm{x}^{3}-1.130610^{4} \mathrm{x}^{4}
$$

with $300<\mathrm{T} / \mathrm{K}<455$. The coordinates of the critical point are : $\mathrm{xCdTe}=0.55$ and $\mathrm{T}=455 \mathrm{~K}$. Taking into account the accuracy of these two series of results, the discreapancy between the coordinates of the critical point are negligeable.

In conclusion, determinations of the molar heat capacity ensures the existence of a miscibility gap in the solid CdTe-HgTe system.

\section{Cd-Ga-In-Sn-Zn system}

A complete study of the thermodynamic properties of a quinary system ( $\mathrm{Cd}-\mathrm{Ga}-\mathrm{In}-\mathrm{Sn}-\mathrm{Zn}$ ) requires theoretically the knowledge of the equivalent properties of 10 binary, 10 ternary and 5 quaternary systems.

The enthalpies of formation of several liquid binary, ternary, quaternary and quinary liquid alloys were determined by direct reaction calorimetry at high temperature on large molar fraction ranges by our group. These measurements were performed using a high temperature Calvet calorimeter or a very high temperature calorimeter equipped with an automatized thermostated charger.

The alloying process was performed in graphite crucible under a high purity argon atmosphere ( before entering in the calorimetric cell, the argon flow was passed over titanium sponge heated at $1120 \mathrm{~K}$ ). The calorimeter was calibrated by Joule effect and by drops of $\alpha$-alumina (NIST) or by supplementary additions of the first metal. 
The uncertainty of the results depends of the number of the components. Errors of the results were estimated of about $1 \%$ for a binary system and of about $5-7 \%$ for a quinary system.

Previously, the available thermodynamic data of the binary alloys ( $\mathrm{Cd}-\mathrm{Ga}, \mathrm{Cd}-\mathrm{In}, \mathrm{Cd}-\mathrm{Sn}, \mathrm{Cd}-\mathrm{Zn}, \mathrm{Ga}-\mathrm{In}, \mathrm{Ga}-$ Sn, Ga-Zn, In-Sn, In-Zn, Sn-Zn) and of ternary alloys ( Ga-In-Sn, Ga-In-Zn,Ga-Sn-Zn, Cd-Ga-In) were analysed. Moreover we have measured the missing enthalpies of formation of $\mathrm{Cd}(0.33) \mathrm{Ga}(0.33) \mathrm{Sn}(0.33)$ and $\mathrm{Cd}(0.33) \mathrm{Ga}(0.33) \mathrm{Zn}(0.33)$ liquid alloys.

The enthalpies of formation of the following liquid quaternary systems have been measured :

\section{Ga-In-Sn-Zn subsystem}

-by dropping of $\mathrm{Zn}$ metal in the $\mathrm{Ga}(0.33) \operatorname{In}(0.33) \mathrm{Sn}(0.33)$ liquid alloy ; .by dropping of $\mathrm{Sn}$ metal in the $\mathrm{Ga}(0.33) \operatorname{In}(0.33) \mathrm{Zn}(0.33)$ liquid alloy ; -by dropping of In metal in the $\mathrm{Ga}(0.33) \mathrm{Sn}(0.33) \mathrm{Zn}(0.33)$ liquid alloy .

The experimental values of the integral molar enthaly of formation at the barycentric point are respectively : $2,269 \mathrm{~kJ} \cdot \mathrm{mol}^{-1}$ (addition of $\mathrm{Zn}$ ), 2,364 kJ.mol-1 (addition of Sn) and 2,343 kJ.mol-1 (addition of In). These results are in a good agreement( mean value $\Delta \Delta_{\mathrm{mix}} \mathrm{H}_{\mathrm{m}}=2.325 \mathrm{~kJ} . \mathrm{mol}-1$ ).

\section{Cd-Ga-In-Sn subsystem}

-by dropping of Cd metal in the Ga(0.33)In(0.33)Sn(0.33) liquid alloy ;

-by dropping of $\mathrm{Sn}$ metal in the $\mathrm{Cd}(0.33) \mathrm{Ga}(0.33) \operatorname{In}(0.33)$ liquid alloy;

.by dropping of In metal in the $\mathrm{Cd}(0.33) \mathrm{Ga}(0.33) \mathrm{Sn}(0.33)$ liquid alloy.

At the barycentre of this quaternary alloy the experimental values of $\Delta$ mix $H_{m}$ are : $1,666 \mathrm{~kJ}^{\mathrm{mol}}-1$ ( addition of Cd), 1,965 kJ.mol-1 (addition of Sn) and 2,087 kJ.mol-1 (addition of In). The value obtained by drops of cadmium seems too low. So $\Delta_{\text {mix }} H_{m}=2,036 \mathrm{~kJ} \cdot \mathrm{mol}^{-1}$ will be used for the calculations.

\section{Cd-Ga-In-Zn subsystem}

-by dropping of $\mathrm{Cd}$ metal in the $\mathrm{Ga}(0.33) \operatorname{In}(0.33) \mathrm{Zn}(0.33)$ liquid alloy ;

-by dropping of In metal in the $\mathrm{Cd}(0.33) \mathrm{Ga}(0.33) \mathrm{Zn}(0.33)$ liquid alloy ;

by dropping of $\mathrm{Zn}$ metal in the $\mathrm{Cd}(0.33) \mathrm{Ga}(0.33) \operatorname{In}(0.33)$ liquid alloy.

At the barycentric composition, the values of the enthalpy of mixing are : $2,559 \mathrm{~kJ} \cdot \mathrm{mol}^{-1}$ (addition of $\mathrm{Zn}$ ), $2,998 \mathrm{~kJ} \cdot \mathrm{mol}^{-1}$ (addition of $\mathrm{Cd}$ ) and 3,195 kJ.mol-1 (addition of In). $\Delta_{\text {mix }} \mathrm{H}_{\mathrm{m}}=3,096 \mathrm{~kJ} \cdot \mathrm{mol}^{-1}$ will be used.

Using the same method, the enthalpies of formation of the Cd-Ga-In-Sn- $\mathrm{Zn}$ liquid system have been investigated. Pure cadmium, tin and zinc have been added at $730 \mathrm{~K}$ to $\mathrm{Ga}(0.25) \operatorname{In}(0.25) \operatorname{Sn}(0.25) \mathrm{Zn}(0.25)$, $\mathrm{Cd}(0.25) \mathrm{Ga}(0.25) \operatorname{In}(0.25) \mathrm{Zn}(0.25)$ and $\mathrm{Cd}(0.25) \mathrm{Ga}(0.25) \operatorname{In}(0.25) \mathrm{Sn}(0.25)$ quaternary liquid alloys. Experimental results are reported on the graphs (Fig. 5 and 6) and Table 1. At the equimolar composition the enthalpy of formation obtained by dropping cadmium or zinc metal are in good agreement ; the value obtained by adding tin metal is too low.

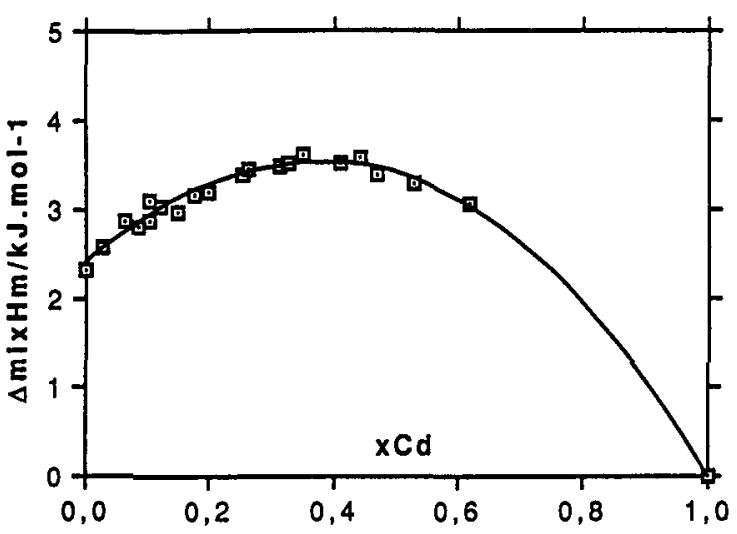

Fig. 5 : Integral molar enthalpy of formation (in $\mathrm{kJ} \cdot \mathrm{mol}-1$ ) of $\mathrm{Cd}-\mathrm{Ga}-\mathrm{In}-\mathrm{Sn}-\mathrm{Zn}$ system from the $\mathrm{Ga}(0.25) \operatorname{In}(0.25) \operatorname{Sn}(0.25) \mathrm{Zn}(0.25)$ liquid alloy at $730 \mathrm{~K}$.

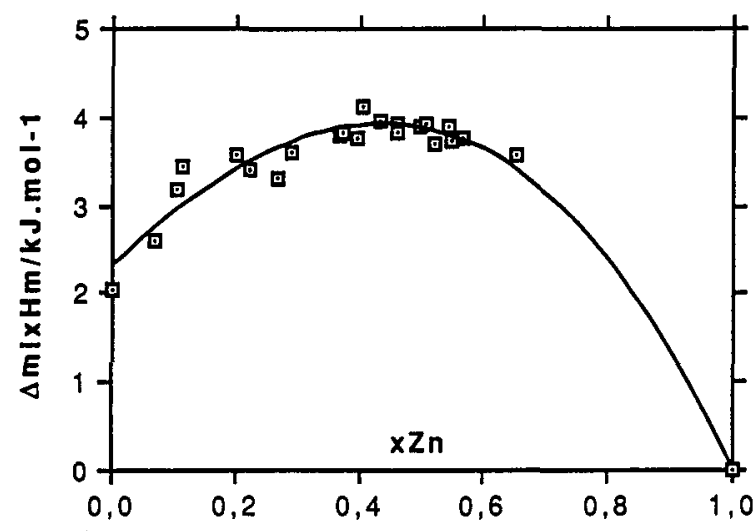

Fig. 6 : Integral molar enthalpy of formation (in kJ.mol-1) of Cd-Ga-In-Sn-Zn system from the $\mathrm{Cd}(0.25) \mathrm{Ga}(0.25) \operatorname{In}(0.25) \mathrm{Sn}(0.25)$ liquid alloy at $730 \mathrm{~K}$. 
Table 1 : Enthalpies of formation of the liquid Cd-Ga-In-Sn-Zn system at $730 \mathrm{~K}$.

\begin{tabular}{|c|c|c|c|}
\hline$T=730 \mathrm{~K}$ & $\mathrm{Ga}(0.25) \ln (0.25) \mathrm{Sn}(0.25) \mathrm{Zn}(0.25)$ & $T=730 \mathrm{~K}$ & $\mathrm{Ga}(0.25) \ln (0.25) \mathrm{Sn}(0.25) \mathrm{Zn}(0.25)$ \\
\hline$x \mathrm{Cd}$ & $\Delta \mathrm{mixHm} / \mathrm{J} . \mathrm{mol}-1$ & $x \mathrm{Cd}$ & $\Delta \mathrm{mixHm} / \mathrm{J} . \mathrm{mol}-1$ \\
\hline 0.000 & 2325 & 0.256 & 3379 \\
\hline 0.029 & 2572 & 0.265 & 3443 \\
\hline 0.064 & 2886 & 0.315 & 3496 \\
\hline 0.088 & 2812 & 0.326 & 3510 \\
\hline 0.103 & 3093 & 0.352 & 3628 \\
\hline 0.105 & 2873 & 0.411 & 3510 \\
\hline 0.123 & 3042 & 0.439 & 3593 \\
\hline 0.149 & 2968 & 0.469 & 3383 \\
\hline 0.176 & 3159 & 0.526 & 3283 \\
\hline 0.200 & 3188 & 0.617 & 3058 \\
\hline$T=730 \mathrm{~K}$ & $\mathrm{Cd}(0.25) \mathrm{Ga}(0.25) \ln (0.25) \mathrm{Zn}(0.25)$ & $T=730 \mathrm{~K}$ & $\mathrm{Cd}(0.25) \mathrm{Ga}(0.25) \ln (0.25) \mathrm{Zn}(0.25)$ \\
\hline$x S n$ & $\Delta m i x H m / J . m o l-1$ & $x S n$ & $\Delta \mathrm{mixHm} / \mathrm{J} . \mathrm{mol}-1$ \\
\hline 0.000 & 3096 & 0.320 & 2524 \\
\hline 0.071 & 3116 & 0.401 & 2379 \\
\hline 0.136 & 2691 & 0.420 & 2215 \\
\hline 0.154 & 2803 & 0.461 & 2271 \\
\hline 0.196 & 2744 & 0.481 & 1919 \\
\hline 0.253 & 2563 & 0.505 & 2003 \\
\hline 0.268 & 2496 & 0.510 & 1761 \\
\hline 0.301 & 2458 & 0.539 & 1622 \\
\hline$T=730 \mathrm{~K}$ & $\mathrm{Cd}(0.25) \mathrm{Ga}(0.2 \mathrm{~s}) \ln (0.25) \mathrm{Sn}(0.25)$ & $\mathrm{T}=730 \mathrm{~K}$ & $\mathrm{Cd}(0.25) \mathrm{Ga}(0.25) \ln (0.25) \operatorname{Sn}(0.25)$ \\
\hline$x \mathrm{Zn}$ & $\Delta \mathrm{mixHm} / \mathrm{J}$ mol-1 & $x Z n$ & $\Delta \mathrm{mixHm} / \mathrm{J}$.mol-1 \\
\hline 0.000 & 2036 & 0.407 & 4120 \\
\hline 0.067 & 2582 & 0.435 & 3971 \\
\hline 0.103 & 3171 & 0.460 & 3925 \\
\hline 0.115 & 3452 & 0.461 & 3820 \\
\hline 0.200 & 3586 & 0.498 & 3904 \\
\hline 0.226 & 3423 & 0.507 & 3925 \\
\hline 0.269 & 3301 & 0.521 & 3715 \\
\hline 0.292 & 3598 & 0.543 & 3887 \\
\hline 0.372 & 3799 & 0.548 & 3720 \\
\hline 0.375 & 3841 & 0.566 & 3782 \\
\hline 0.399 & 3770 & 0.654 & 3568 \\
\hline
\end{tabular}

During the last thirty years, several models (empirical and theoretical models) were proposed to predict the thermodynamic properties of ternary alloys. With empirical models it is well-known that thermodynamic properties of ternary mixtures can be computed from equivalent thermodynamic values of the limiting binary system.

In 1990, for ternary alloys, a general three-factors regular-type model then a general multifactor regular-type model have been presented by Wang and co-workers ( ref. 11 ). These two models reproduced all the wellknow special models ( Kohler, Bonnier, Muggianu, Toop,...) and several dozen of new ones. In 1991, Silhol ( ref.12) in her thesis extended these relations to n-components systems. In the same work, Silhol proposed also an extension of the "surrounded atom model" to quaternary and quinary alloys and compared experimental and predicted results.

If for ternary metallic systems, it is sometimes possible to find a good representation of enthalpy of formation by using an empirical model, for quaternary and quinary systems a satisfactory fit between experimental and predicted values from the same empirical model is very scarce. For instance, experimental results obtained for the quaternary are in good agreement with those obtained by using the Toop model (Fig. 7); on the other hand, for the quinary alloy a better representation was obtained with the Hoch model ( Fig. 8).

For many other systems ( $\mathrm{Ag}-\mathrm{Au}-\mathrm{Si}, \mathrm{Ag}-\mathrm{Au}-\mathrm{Ge}, \mathrm{Pd}-\mathrm{Ni}-\mathrm{Ga}, \mathrm{Pd}-\mathrm{Ni}-\mathrm{In}, . .$. ), we met the same difficulty to predict the excess function of formation. 


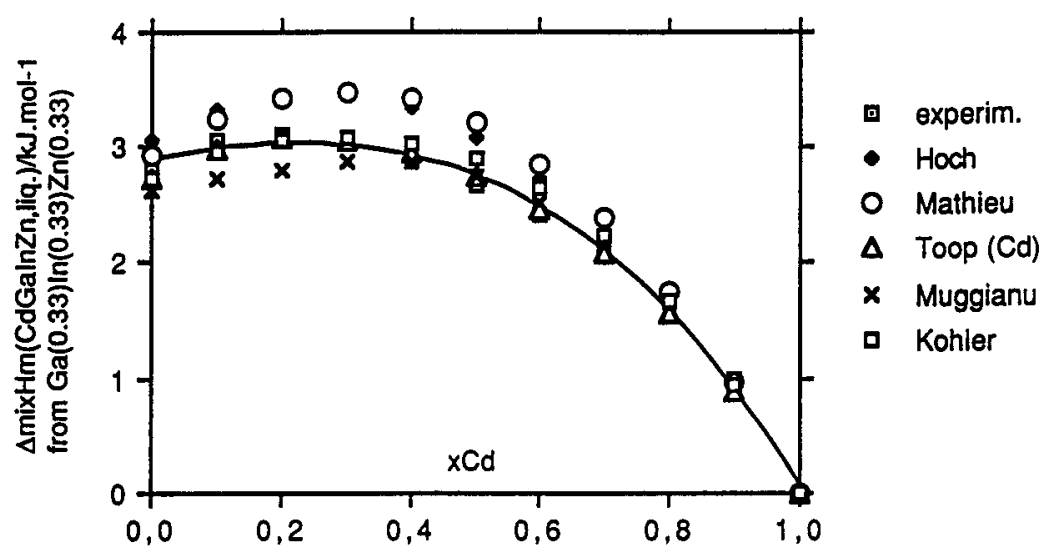

Fig. 7 : Experimental and calculated integral molar enthalpy of formation (in kJ.mol-1) of liquid Cd-Ga-In-Zn system at $730 \mathrm{~K}$.

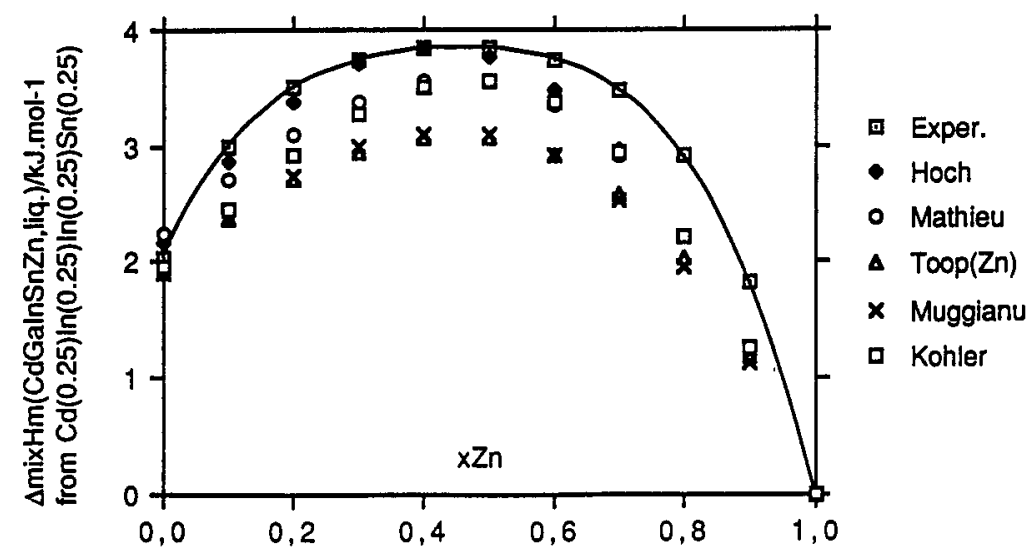

Fig. 8 : Experimental and calculated integral molar enthalpy of formation (in $\mathrm{kJ} . \mathrm{mol}^{-1}$ ) of liquid Cd-Ga-In-Sn-Zn system at $730 \mathrm{~K}$.

\section{CONCLUSION}

In materials science, accurate high temperature calorimetric measurements are fairly often unavoidable to understand the behaviour of materials. So it is most important to have the will to develop precise calorimetric techniques to measure enthalpy of formation and molar heat capacity of n-component materials.

Acknowledgements I am most grateful to a number of my colleagues who contributed valuable comments or who have made available several results (in particular Dr. M. Gaune-Escard, Prof. M. Gambino, Dr. V. Vassiliev and N. Silhol).

\section{REFERENCES}

1. J.L. Jorda , JCAT XXII, $143-149$ (1991).

2. J.P. Bros, $J$, of the Less-Common Metals 154, 9-30 (1989).

3. F. Sommer, J. Thermal Analysis 33, 15-30 (1988).

4. R. Capelli, R. Ferro and A. Borsese, Thermochimica Acta 10, 13-20 (1974).

5. NIST : National Institute of Standards and Technology.

6. R. Hultgren, P.D. Desai, D.T Hawkins, M. Gleiser, K.K. Kelley, D.D. Wagman

"Selected values of the Thermodynamic Properties of the Elements"

Am. Soc. for Metals, Metals Park, Ohio, (1973).

7. A.S. Malkova, V. Jarov, G.I. Shmoilova, A.S. Pashinkin, Zhur, Fiz, Khim. 63, $41-43$ (1989).

8. F. Kelemen, E. Cruceanu, D. Miculescu, Phys. Stat. Sol. 11, 865-872 (1965).

9. V. Vassiliev, M. Gambino, J.P. Bros, J of the Less common metals (in print).

10. V. Vassiliev, M. Gambino, J.P. Bros, J. of the Less common metals (to be published),

11. Z.C.Wang, R. Lûck and B. Predel Calphad 14, n³, 217-234 (1990).

12. N.Silhol ( to be published). 